\title{
Medication-Related Problems in Older People with Multimorbidity in Catalonia: A Real-World Data Study with 5 Years' Follow-Up
}

\author{
Amelia Troncoso-Mariño ${ }^{1,2,+}$, Albert Roso-Llorach ${ }^{3,4}{ }^{(\mathbb{D})}$, Tomás López-Jiménez ${ }^{3,4}$, Noemí Villen ${ }^{1}$, \\ Ester Amado-Guirado ${ }^{1}$, Sergio Fernández-Bertolin ${ }^{3,4}$, Lucía A. Carrasco-Ribelles ${ }^{3,5}$, Josep Ma Borras ${ }^{2}$ (D) \\ and Concepción Violán $4,6,7, *,+$
}

check for updates

Citation: Troncoso-Mariño, A.; Roso-Llorach, A.; López-Jiménez, T.; Villen, N.; Amado-Guirado, E.; Fernández-Bertolin, S.

Carrasco-Ribelles, L.A.; Borras, J.M.; Violán, C. Medication-Related Problems in Older People with Multimorbidity in Catalonia: A Real-World Data Study with 5 Years' Follow-Up. J. Clin. Med. 2021, 10, 709. https://doi.org/ jcm10040709

Academic Editor: Davide Liborio Vetrano

Received: 20 December 2020

Accepted: 8 February 2021

Published: 11 February 2021

Publisher's Note: MDPI stays neutral with regard to jurisdictional claims in published maps and institutional affiliations.

Copyright: (c) 2021 by the authors. Licensee MDPI, Basel, Switzerland. This article is an open access article distributed under the terms and conditions of the Creative Commons Attribution (CC BY) license (https:/ / creativecommons.org/licenses/by/ $4.0 /)$.
1 Medicines Area and Pharmacy Service, Barcelona Territorial Management, Institut Català de la Salut, 08015 Barcelona, Spain; atroncoso@gencat.cat (A.T.-M.); nvillenr.bcn.ics@gencat.cat (N.V.); eamado@gencat.cat (E.A.-G.)

2 Department of Clinical Sciences, University of Barcelona and IDIBELL, L'Hospitalet de Llobregat, 08908 Barcelona, Spain; jmborras@iconcologia.net

3 Fundació Institut Universitari per a la Recerca a l'Atenció Primària de Salut Jordi Gol i Gurina (IDIAPJGol), 08007 Barcelona, Spain; aroso@idiapjgol.org (A.R.-L.); tlopez@idiapjgol.org (T.L.-J.); sfernandez@idiapjgol.org (S.F.-B.); luciacarrascoribelles@gmail.com (L.A.C.-R.)

4 Departament de Pediatria, Obstetricia i Ginecologia i Medicina Preventiva, Universitat Autònoma de Barcelona, 08193 Bellaterra (Cerdanyola del Vallès), Spain

5 Departament de Teoria del Senyal i Comunicacions, Universitat Politècnica de Catalunya, 08034 Barcelona, Spain

6 Research Support Unit Metropolitana Nord, Fundació Institut Universitari per a la Recerca a l'Atenció Primària de Salut Jordi Gol i Gurina (IDIAPJGol), Mataró, 08303 Barcelona, Spain

7 Concepción Violán, Research Support Unit Metropolitana Nord, Fundació Institut Universitari per a la Recerca a l'Atenció Primària de Salut Jordi Gol i Gurina (IDIAPJGol). Mare de Déu de Guadalupe 2, planta $1^{\mathrm{a}}$, Mataro, 08303 Barcelona, Spain

* Correspondence: cviolanf.mn.ics@gencat.cat

+ These authors contributed equally to this work.

Abstract: Aging, multimorbidity, and polypharmacy are associated with medication-related problems (MRPs). This study aimed to assess the association that multimorbidity and mortality have with MRPs in older people over time. We followed multimorbid, older (65-99 years) people in Catalonia from 2012 to 2016, using longitudinal data and Cox models to estimate adjusted hazard ratios (HR). We reviewed electronic health records to collect explanatory variables and MRPs (duplicate therapy, drug-drug interactions, potentially inappropriate medications (PIM), and contraindicated drugs in chronic kidney disease (CKD) or liver disease). There were 723,016 people (median age: 74 years; $58.9 \%$ women) who completed follow-up. We observed a significant $(p<0.001)$ increase in the proportion with at least one MRP (2012: $66.9 \%$ to 2016: 75.5\%); contraindicated drugs in CKD (11.1 to $18.5 \%$ ) and liver disease (3.9 to 5.3\%); and PIMs (62.5 to $71.1 \%$ ), especially drugs increasing fall risk (67.5\%). People with $\geq 10$ diseases had more MRPs (in 2016: PIMs, $89.6 \%$; contraindicated drugs in CKD, 34.4\%; and in liver disease, 9.3\%). All MRPs were independently associated with mortality, from duplicate therapy (HR 1.06; 95\% confidence interval (CI) 1.04-1.08) to interactions (HR 1.60; 95\% CI 1.54-1.66). Ensuring safe pharmacological treatment in elderly, multimorbid patient remains a challenge for healthcare systems.

Keywords: multimorbidity; polypharmacy; drug interactions; duplicate therapy; contraindicated drugs; inappropriate prescribing; primary health care; elderly

\section{Introduction}

More than a third of the population over the age of 50 years in Europe, and 39\% in Spain, presents multimorbidity, defined as having at least two chronic diseases [1]. Age is 
an important determinant of multimorbidity, with people's risk increasing as they grow older [2,3]. Another factor frequently associated with multimorbidity is polymedication (routine use of five or more medications), which often arises from the application of disease-centered clinical practice guidelines, resulting in patients receiving all the indicated treatments for a single pathology, without regard to the other diseases that they may have [4]. Furthermore, treatment indications are seldom adjusted by age group. This aspect, together with the fragmentation of patient care at different healthcare levels, makes it difficult to obtain a holistic understanding of which treatments should be recommended [5].

Medication-related problems (MRPs) are defined as any event or situation wherein medicines may actually or potentially impede the achievement of positive health outcomes [6]. Numerous studies have aimed to quantify MRPs in the hospital setting; however, these problems are also prevalent in primary health care (PHC), where drug treatments are among the most common resources deployed. Polymedication increases the risk of MRPs [7]. As the promotion of patient safety has emerged as a priority for health systems worldwide, in 2017 the World Health Organization (WHO) set a target to cut the global level of severe, avoidable harms related to medications in half by 2022 [8].

The APEAS study, a cross-sectional observational study in 48 PHC centers in 16 semiautonomous regions of Spain, aimed to assess the frequency of adverse events and the factors contributing to their appearance, their severity, and their amenability to prevention [9]. The authors found that medications are a causal factor in $48 \%$ of patient safety incidents in PHC, and of these, 58\% are preventable. Advanced age, polymedication, and multimorbidity are among the risk factors commonly related to MRPs [10], the most serious of which may precipitate an emergency room visit, hospital admission, or death [11,12].

Older patients have certain characteristics that make them especially vulnerable to MRPs. Multimorbidity, polymedication, and changes in drug pharmacodynamics and pharmacokinetics affect most people over the age of 65 years $[13,14]$. Despite the increasing prevalence of multimorbidity and its cascading impacts on MRPs, patients, and health systems, we are not aware of any longitudinal studies that analyze MRP-related risks in older people with multimorbidity. The aims of this study were to evaluate the relationship between MRPs and multimorbidity in patients over 65 years of age and receiving treatment in primary health care (PHC) in Catalonia (Spain) from 2012 to 2016 and to study five-year mortality related to MRPs.

\section{Materials and Methods}

\subsection{Design, Setting, and Study Population}

This retrospective study with longitudinal data took place in Catalonia, a Mediterranean region of Spain with 7,675,217 inhabitants in 2019 [15] and a decentralized, universal health coverage model financed by tax revenue and encompassed under the Spanish National Health System. The Catalan Health Institute oversees 285 PHC centers, serving $5,501,784$ patients ( $74 \%$ of the population); other providers manage the remaining $\mathrm{PHC}$ centers [16].

We included people who: were aged 65 to 99 years on 31 December 2011, lived at least until 31 December 2012 (index date), presented multimorbidity in 2012 or 2016, and made at least one visit to PHC during the five-year study period (2012-2016). The cohort was closed to new entries; attrition was the result of mortality or loss to follow-up due to transfer to different health systems.

\subsection{Dataset}

The Catalan Health Institute's Information System for Research in Primary Care (SIDIAP) stores information from electronic health records (EHR), recorded in PHC centers since 2006 [17]. The SIDIAP database contains anonymized EHRs from PHC and secondary care, with longitudinal information on demographics, socioeconomic status, diagnoses, symptoms, and prescriptions. 
The medication database covers all drugs that are dispensed, subsidized, and billed by the national health service. To identify problems associated with the most relevant medications, we included only drugs for systemic use, excluding medications with local effects (e.g., topical drugs). This database does not cover medication administered in hospitals or dispensed by hospital pharmacies, nor drugs that are not subsidized through public healthcare services.

\subsection{Variables}

All variables were obtained directly from the SIDIAP database [18].

\subsubsection{Chronic Diseases and Multimorbidity}

The SIDIAP database codes diseases using the International Classification of Diseases, 10th revision (ICD-10). We considered multimorbidity as the presence of two or more chronic diseases, defined using 60 selected groups of chronic diseases described in the Swedish National Study of Aging and Care in Kungsholmen (SNAC-K) [19], which was based on ICD-10 diagnostic codes, along with certain clinical, laboratory, and medicationrelated parameters. Patients were classified into four multimorbidity categories according to the number of pathologies they had: 0 to $1 ; 2$ to $4 ; 5$ to 9; and 10 or more chronic diseases. The number of different chronic diseases per patient was collected at baseline (2012) and study end (2016).

\subsubsection{Drugs}

We obtained data for drug exposure from the Pharmacy Invoice Registry. This registry records drugs prescribed by PHC and hospital physicians. The drugs were categorized according to the fourth and fifth levels of the Anatomical Therapeutic Chemical Classification System (ATC) [20], facilitating analysis and interpretation. When the person used three packages of the drug per year during the study period, this was considered chronic use. Packages were defined as the pre-prepared packet of drugs constituting the sales unit of medications available in the pharmacy; these frequently contain the number of doses needed for one month of the indicated treatment. Drugs were coded as dichotomous variables [21], and we classified patients into five categories according to the number of different prescription drugs they were on: $0 ; 1 ; 2$ to $4 ; 5$ to $9 ; 10$ or more.

\subsubsection{Kidney Function}

Impaired kidney function was defined by one of the two following parameters:

(a) Glomerular filtration rate (GFR): using the MDRD-4 IDMS equation, kidney function was determined by estimating the GFR [22]. GFR values of less than $60 \mathrm{~mL} / \mathrm{min} / 1.73 \mathrm{~m}^{2}$ indicated impaired kidney function.

(b) ICD-10 codes for chronic kidney disease (CKD) were taken from SNAC-K criteria [23].

\subsubsection{Liver Function}

Impaired liver function was defined by one of the two following parameters:

(a) Abnormal liver function values: alkaline phosphatase (ALP) $>2 \times 129$ IU/L; alanine transaminase $(\mathrm{ALT})>5 \times 41 \mathrm{IU} / \mathrm{L}$ (men) or ALT $>5 \times 33 \mathrm{IU} / \mathrm{L}$ (women); and gammaglutamyl transpeptidase (GGT) $>61$ IU /L [24].

(b) ICD-10 codes for chronic liver disease were taken from SNAC-K criteria [23].

\subsubsection{Other Variables}

Additional variables collected at baseline and/or study end were sociodemographic variables (age at baseline, gender, and socioeconomic status according to MEDEA index quintiles from least to most deprived) [25] along with the number of total visits to PHC. 


\subsubsection{Medication-Related Problems}

We analyzed the following MRPs: duplicate therapy, drug-drug interactions, potentially inappropriate medications (PIMs) in people aged 65 years or older, contraindicated drugs in CKD, and contraindicated drugs in liver disease. Analysis of the MRPs began by first building tables with medicines and combination drug treatments associated with potential safety concerns:

- Duplicate therapy: prescription of two or more drugs that have the same pharmacological activity. We included duplicate therapies that posed an important clinical risk, according to professional consensus. Our study did not consider combinations of active principles with the same pharmacological action that physicians used to achieve a synergistic effect or to adjust doses [23].

- Drug-drug interaction: when one drug's activity or effect alters the action of another. We focused on interactions that were life-threatening due to therapeutic failure or toxicity, identifying interactions with the highest level of severity (contraindication) from the Thesaurus des interactions médicamenteuses from France's Agence Nationale de Sécurité du Médicament et des Produits de Santé (ANSM) [26] and comparing that information with a second source $[27,28]$ or contrasting it with professional consensus [23].

- Contraindicated drugs in CKD: we identified these drugs from the Catalan Health Department's consensus recommendation for patients with CKD [23,29].

- Contraindicated drugs in liver disease: the Spanish College of Pharmacists database was used to identify these $[23,30]$.

- $\quad$ PIMs in older people ( $\geq 65$ years old): when the risk of adverse events associated with the drug exceeded the expected clinical benefits, and there was no clear scientific evidence pointing to a specific indication or supporting its cost-effectiveness. We primarily used the STOPP/START criteria [31], which was complemented with Beers' criteria [32], PRISCUS, and updates from other sources [33-40]. Different definitions of PIMs exist: Durán et al. defined them as drug combinations with a clinically relevant anticholinergic effect [38], while other authors have included drugs that increase the risk of falling or affect the QT interval with known risk, antiulcer agents administered without considering gastroprotection, and other drugs that are inadvisable for older people or patients needing gastroprotection [23].

\subsection{Ethics}

The Clinical Research Ethics Committee of the Fundació Institut Universitari per a la Recerca a l'Atenció Primària de Salut Jordi Gol i Gurina (IDIAPJGol) (Protocol No: P17/080) approved the study protocol. Data were fully anonymized, and the confidentiality of the EHR was guaranteed at all times in accordance with national and international law.

\subsection{Statistical Analysis}

We used descriptive statistics to summarize the dataset, expressing categorical variables as absolute and relative frequencies and continuous variables as mean (standard deviation, SD) or median (interquartile range, IQR), as appropriate. Differences between multimorbidity groups that completed the follow-up at each study time point were assessed using the chi-square test or the Mann-Whitney U test. The McNemar and Wilcoxon tests were applied to compare prevalence of MRPs and use of PIMs between multimorbidity groups at baseline and at five years' follow-up. The effect of age on the prevalence of MRPs and the use of PIMs were also studied, using data from 2012. For this purpose, two logistic regressions were performed for each MRP and PIM, one only with age and the other by multimorbidity group at baseline, adjusting for age. Multinomial logistic regressions were used to study the influence on the use of PIMs in terms of their anticholinergic effect-anticholinergic load, in both cases.

To estimate mortality hazard for each MRP (duplicate therapy, drug-drug interactions, contraindicated drugs in CKD, contraindicated drugs in liver disease, and PIMs), we fitted Cox proportional-hazards regression models. Length of follow-up was the time elapsed 
from the index date to all-cause death. For the survival analysis, we followed patients until loss to follow-up (censored) or end of observation. Hazard ratios (HRs) and 95\% confidence intervals (CIs) were adjusted for age, sex, socioeconomic status (MEDEA index), and level of multimorbidity at baseline. The proportional hazard assumption was assessed by means of the Schoenfeld residuals. We employed multiple imputation to minimize any selection bias stemming from missing values for MEDEA (7\%) and chained equations to obtain seven imputed datasets. The multiple imputation datasets were incorporated into the final models according to Rubin's rules for combining effect estimates and standard errors, which allowed for some uncertainty related to missing data.

Analyses were performed using SPSS for Windows (version 25, SPSS Inc., New York, NY, USA), Stata 15 Stata/MP (version 15 for Windows, Stata Corp. LP, College Station, TX, USA), and R (version 4.0.3, R Foundation for Statistical Computing, Vienna, Austria). $p$ values of less than 0.05 were considered significant.

\section{Results}

A total of 916,619 people aged 65 years or older were included in the database; 853,085 met the multimorbidity criteria, and 723,016 of these completed five years of follow-up, as shown in Figure 1. This population's median age was 74 years (IQR 68 to 79), and 58.9\% were women. At five years, there was an increase in the proportion of people taking 5 to 9 drugs $(39.8 \%$ vs. $43.1 \%, p<0.001)$ and more than 10 drugs $(12.6 \%$ vs. $15.4 \%, p<0.001)$. Likewise, a higher percentage of patients presented altered liver or kidney function and visited PHC 10 times or more per year, as shown in Table 1.

MRPs were highly prevalent in the study population and increased over time: $66.9 \%$ of the patients had at least one MRP in 2012, compared to 75.5\% in 2016, as shown in Figure 2a. Changes in the type of MRP varied over the study period, with a drop in duplicate therapies ( $11.3 \%$ vs. $6.2 \%$ ) and drug-drug interactions ( $0.9 \%$ vs. $0.5 \%)$. In contrast, the use of contraindicated medicines in CKD and liver disease as well as PIMs had risen by study end, as shown in Figure $2 b$.

In all cases, patients' MRPs increased with the number of chronic diseases; those with 10 or more had the highest prevalence of MRPs both at baseline and study end. At the end of follow-up, $89.6 \%$ of this subgroup were taking PIMs; $34.4 \%$, contraindicated drugs with CKD; and $10.1 \%$, duplicate therapy; smaller proportions had other MRPs, as shown in Table 2. In addition, after adjusting for age, the association between MRPs and multimorbidity was still significant, as shown in Table S1. The most common PIMs in the whole study population at five-year follow-up were drugs increasing the risk of falling (67.5\%); this figure was higher in the subgroup with 10 or more comorbidities, as shown in Table 3. In 2016, 48.4\% of the study population was taking at least two PIMs, along with $8.3 \%$ who were taking at least two contraindicated drugs in CKD, and $2.9 \%$, at least two contraindicated drugs in liver disease, as shown in Table S2.

The most common contraindicated drugs in CKD were metformin $(4.3 \%)$, hydroch lorothiazide (both as monotherapy $(2.8 \%)$ and in fixed-dose combination with enalapril $(2.1 \%)$ ), and citalopram (1.6\%), as shown in Table S3. In liver disease, the main contraindicated drugs were simvastatin $(1.9 \%)$, furosemide $(1.2 \%)$, and metformin $(1.0 \%)$, as shown in Table S4. The most frequent PIMs were omeprazole, used without gastroprotective criteria (23.3\%); lorazepam, due to the increased risk of falling (14.8\%); and bisoprolol, in patients concomitantly taking anticholinesterase, due to the risk of cardiac conduction failure, syncope, or heart damage (11.6\%), as shown in Table S5.

People with MRPs were at higher risk of death-especially in the case of drug-drug interactions (HR 1.62, 95\% CI 1.55 to 1.70), followed by patients taking contraindicated drugs in liver disease (HR 1.59, 95\% CI 1.56 to 1.63) and those on PIMs (HR 1.31, 95\% CI 1.29 to 1.32), as shown in Table 4. 


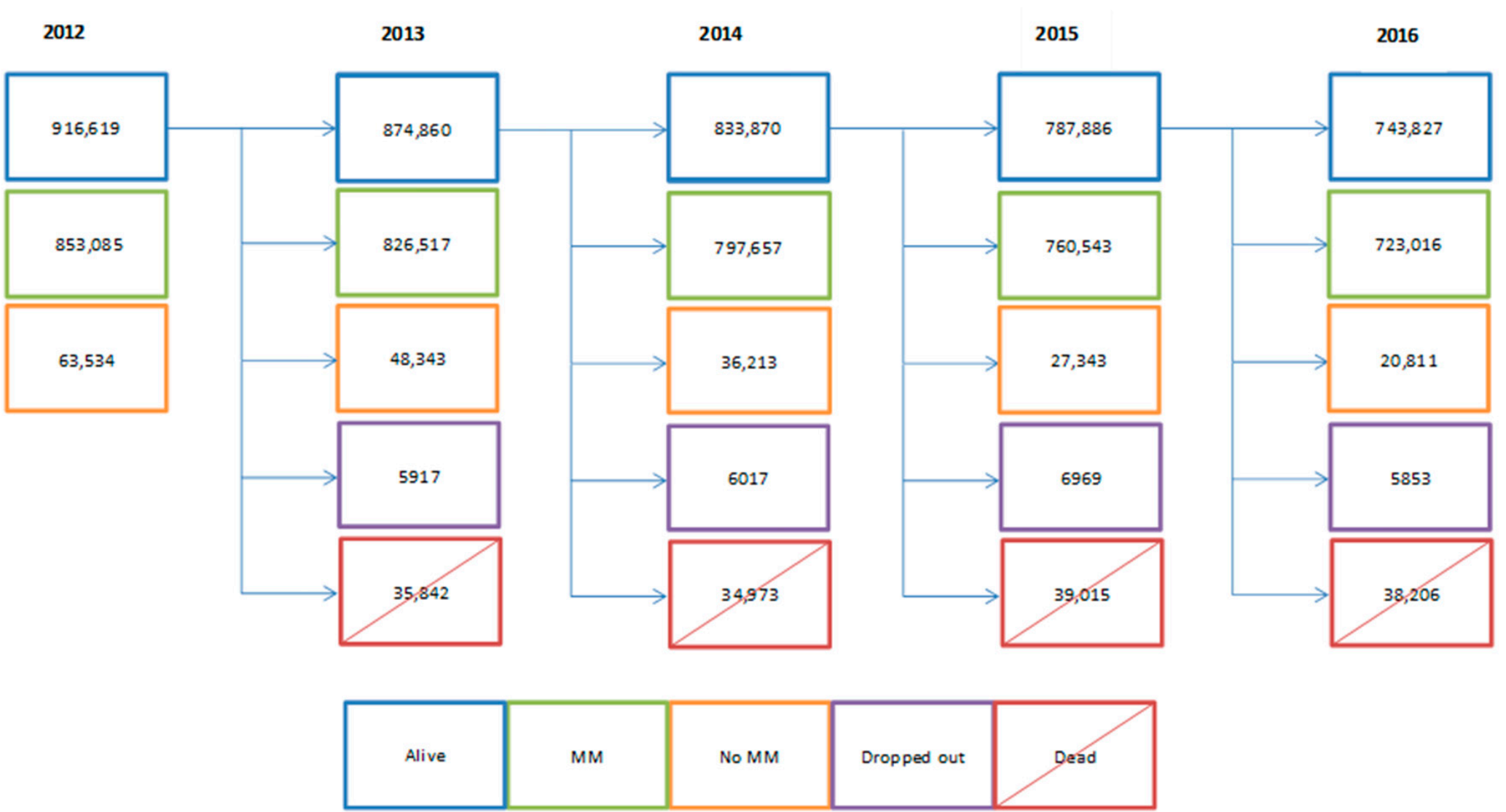

Figure 1. Longitudinal flow chart of patients meeting initial inclusion criteria, without consideration for the multimorbidity criterion $(2012-2016$; $\mathrm{N}=916,619$ people). 
(a)

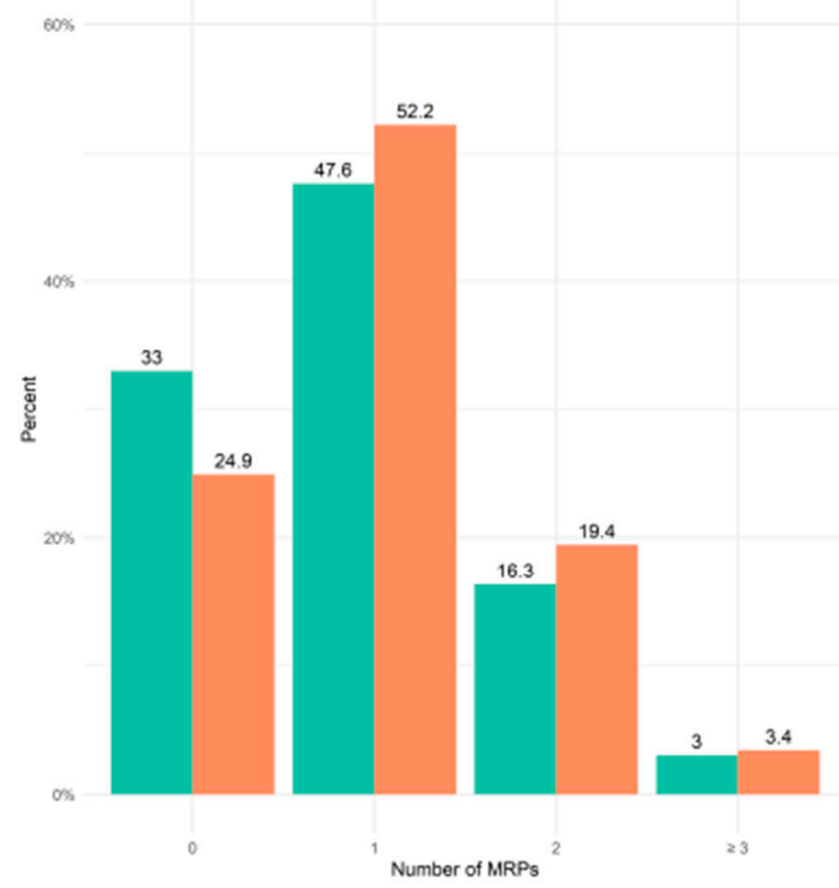

(b)

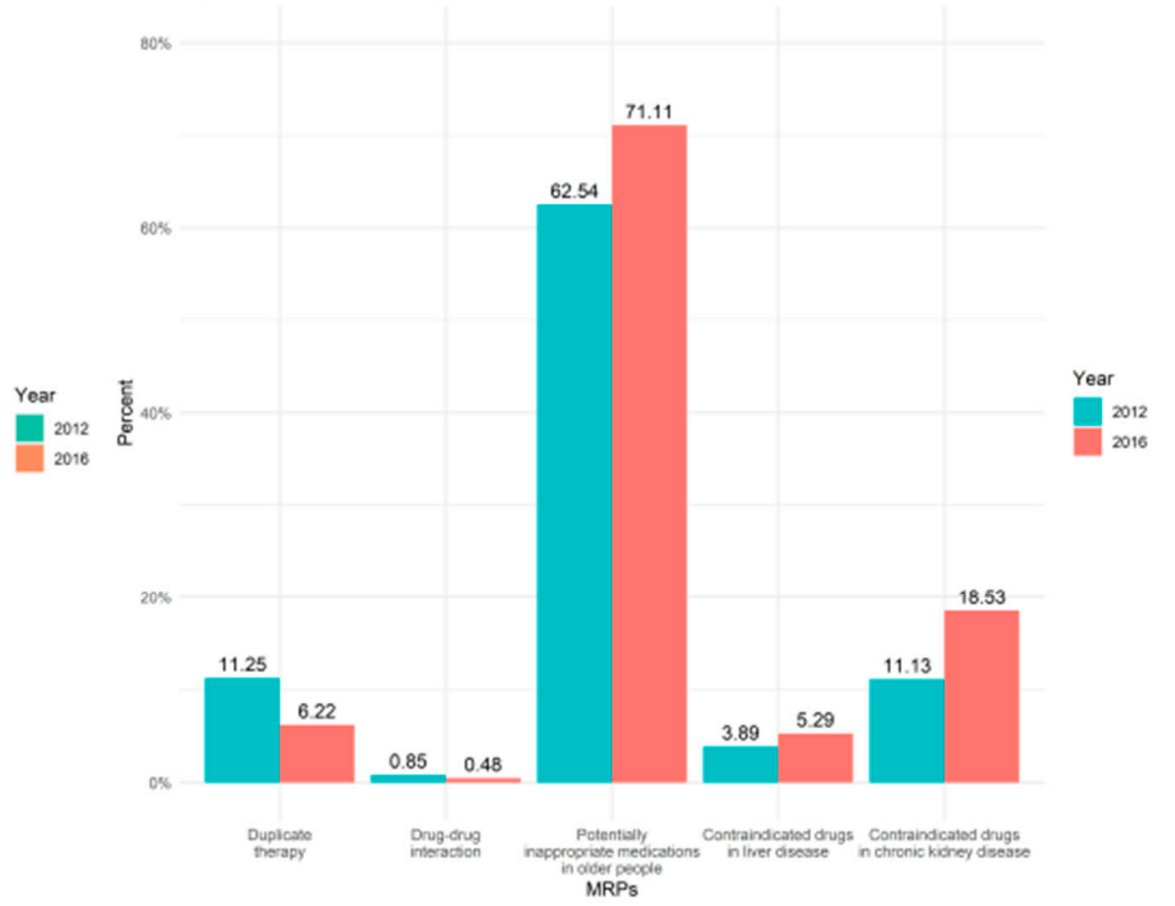

Figure 2. (a) Frequencies and (b) types of medication-related problems (MRPs) in older people with multimorbidity at baseline (2012) and at end of study $(2016)(\mathrm{N}=723,016)$. 
Table 1. Descriptive characteristics of older people by multimorbidity groups at baseline and at the end of the study $(\mathrm{N}=723,016)$.

\begin{tabular}{|c|c|c|c|c|c|c|c|c|}
\hline \multirow[b]{2}{*}{ Variables } & \multicolumn{6}{|c|}{ N Comorbidities } & & \\
\hline & \multicolumn{2}{|c|}{$\begin{array}{c}2-4 \text { Diseases } \\
\mathrm{N}=137,799 \\
n(\%) *\end{array}$} & \multicolumn{2}{|c|}{$\begin{array}{c}\text { 5-9 Diseases } \\
\begin{array}{c}\mathrm{N}=393,672 \\
n(\%)\end{array}\end{array}$} & \multicolumn{2}{|c|}{$\begin{array}{c}\geq 10 \text { Diseases } \\
\mathrm{N}=191,545 \\
n(\%) *\end{array}$} & \multicolumn{2}{|c|}{$\begin{array}{c}\text { Total } \\
\mathrm{N}=723,016 \\
n(\%) *\end{array}$} \\
\hline Sex, women, $n(\%)$ & \multicolumn{2}{|c|}{$73,137(53.1)$} & \multicolumn{2}{|c|}{$229,870(58.4)$} & \multicolumn{2}{|c|}{$123,014(64.2)$} & \multicolumn{2}{|c|}{$426,021(58.9)$} \\
\hline Age, median (IQR) & \multicolumn{2}{|c|}{$71.00[67.00,76.00]$} & \multicolumn{2}{|c|}{$73.00[68.00 ; 79.00]$} & \multicolumn{2}{|c|}{$76.00[71.00 ; 80.00]$} & \multicolumn{2}{|c|}{$74.00[68.00 ; 79.00]$} \\
\hline Rural & \multicolumn{2}{|c|}{$30,094(22.5)$} & \multirow{2}{*}{\multicolumn{2}{|c|}{$78,760(20.6)$}} & \multirow{2}{*}{\multicolumn{2}{|c|}{$31,752(17.2)$}} & \multirow{2}{*}{\multicolumn{2}{|c|}{$140,606(20.1)$}} \\
\hline MEDEA Index † & \multirow{2}{*}{\multicolumn{2}{|c|}{26,608 (19.9) }} & & & & & & \\
\hline Q1 & & & \multicolumn{2}{|c|}{$63,322(16.6)$} & \multicolumn{2}{|c|}{$27,986(15.1)$} & \multicolumn{2}{|c|}{$117,916(16.8)$} \\
\hline Q3 & \multicolumn{2}{|c|}{$20,866(15.6)$} & \multicolumn{2}{|c|}{$63,789(16.7)$} & \multicolumn{2}{|c|}{$31,480(17.0)$} & \multicolumn{2}{|c|}{$116,135(16.6)$} \\
\hline$\widehat{\mathrm{Q}} 4$ & \multicolumn{2}{|c|}{$19,243(14.4)$} & \multicolumn{2}{|c|}{$61,187(16.0)$} & 32, & 7.4) & 112 & 16.1) \\
\hline Q5 & 14, & & 52, & 3.7) & 31, & $7.1)$ & 98, & $4.1)$ \\
\hline Number of drugs & 2012 & 2016 & 2012 & 2016 & 2012 & 2016 & 2012 & 2016 \\
\hline 0 & $34,937(25.4)$ & $26,903(19.5)$ & $32,578(8.3)$ & $16,833(4.3)$ & $7104(3.7)$ & $1918(1.0)$ & $74,619(10.3)$ & $45,654(6.3)$ \\
\hline 1 & $21,226(15.4)$ & $21,234(15.4)$ & $24,267(6.2)$ & $19,235(4.9)$ & $2774(1.5)$ & $1661(0.9)$ & $48,267(6.7)$ & $42,130(5.8)$ \\
\hline $2-4$ & $57,435(41.7)$ & $62,554(45.4)$ & $136,887(34.8)$ & $130,158(33.1)$ & $26,751(14.0)$ & $19,860(10.4)$ & $221,073(30.6)$ & $212,572(29.4)$ \\
\hline $5-9$ & $22,892(16.6)$ & $25,954(18.8)$ & $169,574(43.1)$ & $191,213(48.6)$ & $95,389(49.8)$ & $94,522(49.4)$ & $287,855(39.8)$ & $311,689(43.1)$ \\
\hline Number of visits & & & & & & & & \\
\hline 0 & $13,639(9.9)$ & $10,299(7.5)$ & $12,374(3.1)$ & $5901(1.5)$ & 3147 (1.6) & $858(0.5)$ & $29,160(4.0)$ & $17,058(2.4)$ \\
\hline 1 & $11,341(8.2)$ & $10,419(7.6)$ & $10,723(2.7)$ & $9130(2.3)$ & $1523(0.8)$ & $1276(0.7)$ & $23,587(3.3)$ & $20,825(2.9)$ \\
\hline $2-4$ & 38,129 (27.7) & $38,161(27.7)$ & $57,257(14.5)$ & $52,043(13.2)$ & $10,123(5.3)$ & 8725 (4.6) & $105,509(14.6)$ & $98,929(13.7)$ \\
\hline $5-9$ & $45,344(32.9)$ & $46,684(33.9)$ & $128,738(32.7)$ & $123,262(31.3)$ & $37,760(19.7)$ & $32,163(16.8)$ & $211,842(29.3)$ & $202,109(28.0)$ \\
\hline$\geq 10$ & $29,346(21.3)$ & $32,236(23.4)$ & $184,580(46.9)$ & $203,336(51.7)$ & $138,992(72.6)$ & $148,523(77.5)$ & $352,918(48.8)$ & $384,095(53.1)$ \\
\hline $\bar{C} K D$ & $6809(4.9)$ & $10,907(7.9)$ & $53,110(13.5)$ & $96,875(24.6)$ & $49,182(25.7)$ & $88,954(46.4)$ & $109,101(15.1)$ & $196,736(27.2)$ \\
\hline $\begin{array}{l}\text { Chronic liver } \\
\text { disease }\end{array}$ & 4495 (3.3) & $5228(3.8)$ & $22,105(5.6)$ & $26,888(6.8)$ & $16,883(8.8)$ & $22,511(11.8)$ & $43,483(6.0)$ & 54,627 (7.6) \\
\hline
\end{tabular}

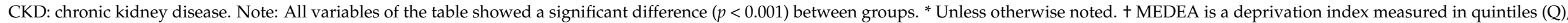
from Q1 (least deprived) to Q5 (most deprived). Missing values $n=22,178$. IQR: interquartile range. 
Table 2. Medication-related problems in older people by multimorbidity group at baseline and at the end of the study $(\mathrm{N}=723,016)$.

\begin{tabular}{|c|c|c|c|c|c|c|c|c|}
\hline \multirow{4}{*}{ Medication-Related Problems } & \multicolumn{6}{|c|}{ N Comorbidities } & & \\
\hline & \multicolumn{2}{|c|}{$\begin{array}{c}2-4 \text { Diseases } \\
N=137,799\end{array}$} & \multicolumn{2}{|c|}{$\begin{array}{c}\text { 5-9 Diseases } \\
N=393,672\end{array}$} & \multicolumn{2}{|c|}{$\begin{array}{c}\geq 10 \text { Diseases } \\
N=191,545\end{array}$} & \multicolumn{2}{|c|}{$\begin{array}{c}\text { Total } \\
\mathrm{N}=723,016\end{array}$} \\
\hline & \multicolumn{2}{|c|}{$n(\%)$} & \multicolumn{2}{|c|}{$n(\%)$} & \multicolumn{2}{|c|}{$n(\%)$} & \multicolumn{2}{|c|}{$n(\%)$} \\
\hline & 2012 & 2016 & 2012 & 2016 & 2012 & 2016 & 2012 & 2016 \\
\hline Duplicate therapy & $6853(5.0)$ & $3565(2.6)$ & $40,507(10.3)$ & $22,070(5.6)$ & $33,997(17.8)$ & $19,370(10.1)$ & $81,357(11.3)$ & $45,005(6.2)$ \\
\hline Drug-drug interactions & $396(0.3)$ & $172(0.1)$ & $2616(0.7)$ & $1473(0.4)$ & $3100(1.6)$ & $1817(1.0)$ & $6112(0.9)$ & $3462(0.5)$ \\
\hline Contraindicated drugs in CKD & $3606(2.6)$ & $5199(3.8)$ & $37,386(9.5)$ & $62,808(16.0)$ & $39,474(20.6)$ & $65,962(34.4)$ & $80,466(11.1)$ & $133,969(18.5)$ \\
\hline Potentially inappropriate medication & $49,999(36.3)$ & $60,353(43.8)$ & $245,447(62.4)$ & $282,150(71.7)$ & $156,710(81.8)$ & $171,641(89.6)$ & $452,156(62.5)$ & $514,144(71.1)$ \\
\hline
\end{tabular}

CKD: chronic kidney disease. Note: All variables of the table showed a significant difference $(p<0.001)$ between groups.

Table 3. Potentially inappropriate medications in older people by multimorbidity group at baseline and at the end of the study $(\mathrm{N}=514,144)$.

\begin{tabular}{|c|c|c|c|c|c|c|c|c|}
\hline \multirow{3}{*}{ Reason for Drug Inappropriateness } & \multicolumn{8}{|c|}{ N Comorbidities } \\
\hline & \multicolumn{2}{|c|}{$\begin{array}{c}2-4 \text { Diseases } \\
\mathrm{N}=60,353 \\
n(\%)\end{array}$} & \multicolumn{2}{|c|}{$\begin{array}{c}\text { 5-9 Diseases } \\
\mathrm{N}=\mathbf{2 8 2 , 1 5 0} \\
n(\%)\end{array}$} & \multicolumn{2}{|c|}{$\begin{array}{c}\geq 10 \text { Diseases } \\
\mathrm{N}=171,641 \\
n(\%)\end{array}$} & \multicolumn{2}{|c|}{$\begin{array}{c}\text { Total } \\
\mathrm{N}=514,144 \\
n(\%)\end{array}$} \\
\hline & 2012 & 2016 & 2012 & 2016 & 2012 & 2016 & 2012 & 2016 \\
\hline \multicolumn{9}{|l|}{ Anticholinergic effect-anticholinergic load* } \\
\hline Score $=1$ & $7011(11.6)$ & $10,910(18.1)$ & $42,699(15.1)$ & $61,400(21.8)$ & $34,069(19.9)$ & $45,155(26.3)$ & $83,779(16.3)$ & $117,465(22.9)$ \\
\hline Score $=2$ & $3614(6.0)$ & $5104(8.5)$ & $25,833(9.2)$ & $32,771(11.6)$ & $22,269(13.0)$ & $27,232(15.9)$ & $51,716(10.1)$ & $65,107(12.7)$ \\
\hline Score $=3-5$ & $1209(2.0)$ & $1499(2.5)$ & $9929(3.5)$ & $13,023(4.6)$ & $11,885(6.9)$ & $15,429(9.0)$ & $23,023(4.5)$ & $29,951(5.8)$ \\
\hline Score $\geq 6$ & $39(0.1)$ & $37(0.1)$ & $307(0.1)$ & $315(0.1)$ & $484(0.3)$ & $436(0.3)$ & $830(0.2)$ & $788(0.2)$ \\
\hline Increase in fall risk & $26,366(43.7)$ & $36,430(60.4)$ & $145,741(51.7)$ & $184,449(65.4)$ & $107,661(62.7)$ & $125,913(73.4)$ & $279,768(54.4)$ & $346,792(67.5)$ \\
\hline Effect on QT interval & $4834(8.0)$ & $6814(11.3)$ & $34,387(12.2)$ & $43,157(15.3)$ & $32,334(18.8)$ & $37,491(21.8)$ & $71,555(13.9)$ & $87,462(17.0)$ \\
\hline $\begin{array}{l}\text { Antiulcer agents without criteria for } \\
\text { gastroprotection }\end{array}$ & $11,821(19.6)$ & $15,761(26.1)$ & $81,766(29.0)$ & $99,292(35.2)$ & $65,395(38.1)$ & $74,812(43.6)$ & $158,982(30.9)$ & $189,865(36.9)$ \\
\hline Other drugs not recommended for older people & $9396(15.6)$ & $24,069(39.9)$ & $72,664(25.8)$ & $141,221(50.1)$ & $65,478(38.2)$ & $109,566(63.8)$ & $147,538(28.7)$ & $274,856(53.5)$ \\
\hline Patients needing gastroprotection & $70(0.1)$ & $132(0.2)$ & $524(0.2)$ & $683(0.2)$ & $344(0.2)$ & $325(0.2)$ & $938(0.2)$ & $1140(0.2)$ \\
\hline
\end{tabular}

Note: All variables of the table showed a significant difference $(p<0.001)$ between groups. ${ }^{*}$ Score $=0$ Not shown. 
Table 4. Mortality related to medication-related problems in older people with multimorbidity at baseline year $(\mathrm{N}=853,085)$.

\begin{tabular}{lccc}
\hline Medication-Related Problems & $\begin{array}{c}\text { HR (Crude) } \\
\mathbf{9 5 \%} \text { CI }\end{array}$ & $\begin{array}{c}\text { Complete Case Analysis } \\
\text { HR (Adjusted) * 95\% CI }\end{array}$ & $\begin{array}{c}\text { Multiple Imputation } \\
\text { HR (Adjusted) * 95\% CI }\end{array}$ \\
\hline $\begin{array}{l}\text { Duplicate therapy } \\
\text { Drug-drug interactions }\end{array}$ & $1.14(1.12-1.16)$ & $1.06(1.04-1.07)$ & $1.06(1.04-1.08)$ \\
Contraindicated drugs in chronic kidney disease & $1.02(1.95-2.10)$ & $1.62(1.55-1.70)$ & $1.60(1.54-1.66)$ \\
Contraindicated drugs in liver disease & $1.59(1.52-1.76)$ & $1.06(1.05-1.08)$ & $1.08(1.06-1.09)$ \\
Potentially inappropriate medication in older & $1.76(1.74-1.78)$ & $1.59(1.56-1.63)$ & $1.54(1.50-1.57)$ \\
people & & $1.31(1.29-1.32)$ & $1.30(1.29-1.32)$ \\
\hline
\end{tabular}

HR: hazard ratio. * Adjusted for age, sex, socioeconomic status (MEDEA index), and level of multimorbidity.

\section{Discussion}

Our results show that MRPs, and especially PIMs, were very prevalent in multimorbid older people both at baseline and at study end, especially in patients with the most comorbidities. Presenting one or more MRPs was associated with a higher risk of mortality at five years' follow-up.

Multimorbidity is associated with the prescription of multiple medications, boosting the risk of exposure to unnecessary drugs and the likelihood of duplicate therapies or interactions, among other MRPs [41]. Aging is associated with diminished renal and liver clearance, primarily due to the reduced blood flow and hepatocyte mass as well as sclerotic changes in the glomeruli [14]. These factors set off changes in drug metabolism and excretion, which can make it necessary to adjust drug dosing or use alternative treatments that are not contraindicated in these situations.

A variety of terminology is used to conceptualize different events or circumstances related to administering medication that could actually or potentially interfere in achieving desired health outcomes, making it extremely difficult to compare the results obtained in different studies [42].

A singular contribution of this study is that it analyzes the prevalence and fiveyear evolution of MRPs in a large cohort of multimorbid older people. To our knowledge, no other studies have reported longitudinal data or trends associated with duplicate therapy or contraindicated drugs in CKD or liver disease after a follow-up period. We observed a decrease in the proportion of patients on duplicate therapy, from $11.3 \%$ at baseline to $6.2 \%$ at five years, which is more similar to the $4.8 \%$ reported in cross-sectional studies [43]. Similarly, we saw a decrease in drug-drug interactions; this result stands in contrast with other studies that not only reported an upward trend, but also a higher overall prevalence of this problem [44]. These differences may be because we excluded over-thecounter medications and dietary supplements from the analysis, instead analyzing only formally contraindicated interactions. In addition, in 2012 the Catalan Health Institute implemented a warning system for clinical histories in PHC to prevent medication-related errors, including interactions and duplications. This policy could have contributed to the decrease in these MRPs over the five-year follow-up, although a specific study investigating this relationship would be needed to confirm this hypothesis.

On the other hand, our results show an increase in the use of contraindicated drugs in CKD, from $11.1 \%$ at baseline to $18.5 \%$ at five years. Cross-sectional studies show wide variations (13 to $80.5 \%$ ) in the proportion of patients with CKD who are prescribed inappropriate drugs in ambulatory care [45]. As in our study, metformin is among the most common medications used inappropriately in these patients [45]. Thus, automated warnings to support dose adjustment in electronic prescription systems may favor appropriate drug use in patients with CKD.

We did not identify PHC studies that analyzed contraindicated drugs in liver disease in older patients. The influence of these pathologies on pharmacokinetics and pharmacodynamics is complex, and currently there is no quantitative method to calculate dose 
adjustments in these patients. These challenges mean that recommendations on drug use are imprecise, and few studies have tried to quantify this type of MRP. However, we observed a high prevalence of this problem, so it needs to be considered when prescribing drugs in older people.

With regard to the number of PIMs in the elderly patient population, the literature reports a wide range and divergent trends. Some studies reported no significant changes over time, while others found, as we did, that this type of MRP tends to increase over follow-up [46,47]. Notably, the proportion of patients taking PIMs was higher in our study (ranging from 62.5 to $71.1 \%$ ) than in others. Diverse factors could play a role in these differences; for example, variations in the criteria used to identify a PIM or in the characteristics of included patients. Regarding the criteria for defining a PIM, we used a comprehensive review, which could have influenced the number of PIMs identified [23].

In our study, we observed that older, multimorbid patients who presented MRPs carry a higher risk of mortality, and the magnitude of this association is highest in those with drug-drug interactions. Mortality associated with drug-related adverse events has mainly been analyzed in the hospital setting, where it represents $0.15 \%$ of all inpatient deaths-double the rate as in the rest of admitted patients [48,49]. Our study corroborates the data reported in a hospital setting from the PHC perspective, highlighting the impact of MRPs for both patients and the health system.

This study is based on a large, high-quality database containing PHC records that are representative of the multimorbid population in Catalonia [18]. In addition, we used validated, clinically driven methodology to measure chronic diseases and polypharmacy, which allows a standardized evaluation of chronic diseases in the European Union [19].

Nevertheless, our study also has some limitations. First of all, we considered only the medications used chronically ( $\geq 3$ packages dispensed per year), thus excluding medications used to treat acute pathologies from the analysis. Secondly, the SIDIAP database only collects information on medications prescribed by PHC and hospital-based physicians that are dispensed in community pharmacies and covered under the national health system, with no data on drugs dispensed in hospital, over-the-counter medications, and those not financed by the health system. These two limitations could have caused us to underestimate the frequency of MRPs [50]. Finally, due to the study methodology, it was not possible to report patients' adherence to treatment.

People with multimorbidity usually receive care from several prescribers, including physicians in PHC and in hospitals [51]. Polymedication is often the result of fragmentation of the health system, together with the application of clinical practice guidelines that focus on a single pathology rather than holistically taking into account the complexity of patients with multimorbidity [4]. Primary care physicians and pharmacists have an important role in reconciling different prescriptions during care transitions and in reviewing treatments in patients with an advanced age and multimorbidity. These professionals can help to align drug regimens with individuals' desired outcomes, weighing the risk-benefit balance of treatments recommended in clinical practice guidelines.

The data on MRPs obtained in this study provide information that could inform the design of programs for preventing MRPs in healthcare institutions. Interventions aimed at avoiding drug-related adverse events could include integrating decision-making aids into EHRs or implementing professional training.

\section{Conclusions}

The high prevalence of MRPs and their possible impact on mortality in elderly patients with multimorbidity suggest that MRPs are a widespread public health problem. Our results show the impact of MRPs when patients have more comorbidities, affecting both patients' health and healthcare services.

Supplementary Materials: The following are available online at https: / www.mdpi.com/2077-0 383/10/4/709/s1, Table S1: Age-adjusted association between medication-related problems and multimorbidity. Table S2: Number of contraindicated drugs in chronic kidney disease and liver 
disease and potentially inappropriate medications in older people by multimorbidity group at the end of the study, $2016(\mathrm{~N}=723,016)$. Table S3: Twenty most contraindicated drugs in chronic kidney disease in older people by multimorbidity group at the end of the study, 2016 ( $N=723,016)$. Table S4: Twenty most contraindicated drugs in liver disease in older people by multimorbidity group at the end of the study, $2016(\mathrm{~N}=723,016)$. Table S5: Twenty most potentially inappropriate medications in older people by multimorbidity group at the end of the study, $2016(\mathrm{~N}=723,016)$.

Author Contributions: All authors contributed to the design of the study, revised the article, and approved the final version. C.V., A.R.-L., E.A.-G. and S.F.-B. obtained the funding. C.V., J.M.B., A.R.-L., A.T.-M. and N.V. drafted the article. N.V., A.T.-M., T.L.-J., A.R.-L., L.A.C.-R., C.V. and S.F.-B. proposed the methodology, conducted the tests, and contributed to the analysis and interpretation of data. A.T.-M., C.V., J.M.B. and N.V. wrote the first draft of the manuscript. N.V., A.T.-M., A.R.-L. and S.F.-B. wrote the first draft of the supplementary file, and all authors contributed ideas, interpreted the findings, and reviewed rough drafts of the manuscript. All authors have read and agreed to the published version of the manuscript.

Funding: This work was supported by a research grant from the Instituto de Salud Carlos III, under the auspices of the Ministry of Science, Innovation and Universities, awarded in the 2016 call under the Health Strategy Action 2013-2016, within the National Research Programme oriented to Societal Challenges, within the Technical, Scientific and Innovation Research National Plan 2013-2016 (grant number PI16/00639), co-funded with the EU European Regional Development Fund and the Department of Health of the Catalan Government, in the 2017 call that awarded subsidies for the Strategic Plan for Research in Health (Pla Estratègic de Recerca i Innovació en Salut, PERIS) 2016-2020, modality research oriented to primary care (grant number SLT002/16/00058) and by the Catalan Government (grant number AGAUR 2017 SGR 578).

Institutional Review Board Statement: The study was conducted according to the guidelines of the Declaration of Helsinki, and approved by the Clinical Research Ethics Committee, Fundació Institut Universitari per a la Recerca a l'Atenció Primària de Salut Jordi Gol i Gurina (IDIAPJGol) (Protocol No: P17/080). All data were anonymized in agreement with national and international law.

Informed Consent Statement: Not applicable.

Data Availability Statement: The datasets are not available, since researchers signed an agreement with the Information System for the Development of Research in Primary Care (SIDIAP) concerning confidentiality and security of the dataset, which forbids providing data to third parties. The SIDIAP is subject to periodic audits.

Acknowledgments: We thank the Catalan Institute of Health and the SIDIAP, which provided the database for the study. The authors are also grateful to Carmen Ibáñez for the administrative support.

Conflicts of Interest: All authors have completed the ICMJE uniform disclosure form at www. icmje.org/coi_disclosure.pdf (accessed date 20 December 2020) and declare: no support from any organization for the submitted work; no financial relationships with any organizations that might have an interest in the submitted work in the previous three years; no other relationships or activities that could have influenced the submitted work.

\section{References}

1. Palladino, R.; Lee, J.T.; Ashworth, M.; Triassi, M.; Millett, C. Associations between Multimorbidity, Healthcare Utilisation and Health Status: Evidence from 16 European Countries. Age Ageing 2016, 45, 431-435. [CrossRef]

2. Violan, C.; Foguet-Boreu, Q.; Flores-Mateo, G.; Salisbury, C.; Blom, J.; Freitag, M.; Glynn, L.; Muth, C.; Valderas, J.M. Prevalence, Determinants and Patterns of Multimorbidity in Primary Care: A Systematic Review of Observational Studies. PLoS ONE 2014, 9, 3-11. [CrossRef]

3. Prados-Torres, A.; Poblador-Plou, B.; Calderón-Larrañaga, A.; Gimeno-Feliu, L.A.; González-Rubio, F.; Poncel-Falcó, A.; SicrasMainar, A.; Alcalá-Nalvaiz, J.T. Multimorbidity Patterns in Primary Care: Interactions among Chronic Diseases Using Factor Analysis. PLoS ONE 2012, 7. [CrossRef] [PubMed]

4. Marengoni, A.; Onder, G. Guidelines, Polypharmacy, and Drug-Drug Interactions in Patients with Multimorbidity: A Cascade of Failure. BMJ 2015, 350, 10-11. [CrossRef] [PubMed]

5. Rijken, M.; Struckmann, V.; Van der Heide, I.; Hujala, A.; Barbabella, F.; Van Ginneken, E.; Shellevis, F. How to Improve Care for People with Multimorbidity in Europe? Eur. Obs. Policy Briefs 2017, 1-31.

6. Pharmaceutical Care Network Europe. Available online: https://www.pcne.org/ (accessed on 3 December 2019). 
7. Prados-Torres, A.; Del Cura-González, I.; Prados-Torres, D.; López-Rodríguez, J.A.; Leiva-Fernández, F.; Calderón-Larrañaga, A.; López-Verde, F.; Gimeno-Feliu, L.A.; Escortell-Mayor, E.; Pico-Soler, V.; et al. Effectiveness of an Intervention for Improving Drug Prescription in Primary Care Patients with Multimorbidity and Polypharmacy: Study Protocol of a Cluster Randomized Clinical Trial (Multi-PAP Project). Implement. Sci. 2017, 12, 1-10. [CrossRef]

8. World Health Organization. Medication Without Harm; World Health Organization: Geneva, Switzerland, 2017 ; p. 16.

9. APEAS Study. Patient Safety in Primary Health Care; Ministry of Health \& Consumer Affairs: Madrid, Spain, 2008.

10. Gnädinger, M.; Conen, D.; Herzig, L.; Puhan, M.A.; Staehelin, A.; Zoller, M.; Ceschi, A. Medication Incidents in Primary Care Medicine: A Prospective Study in the Swiss Sentinel Surveillance Network (Sentinella). BMJ Open 2017, 7, 1-12. [CrossRef]

11. Baena, M.I.; Faus, M.J.; Fajardo, P.C.; Luque, F.M.; Sierra, F.; Martinez-Olmos, J.; Cabrera, A.; Fernandez-Llimos, F.; MartinezMartinez, F.; Jiménez, J.; et al. Medicine-Related Problems Resulting in Emergency Department Visits. Eur. J. Clin. Pharmacol. 2006, 62, 387-393. [CrossRef]

12. Parameswaran Nair, N.; Chalmers, L.; Bereznicki, B.J.; Curtain, C.M.; Bereznicki, L.R. Repeat Adverse Drug Reaction-Related Hospital Admissions in Elderly Australians: A Retrospective Study at the Royal Hobart Hospital. Drugs Aging 2017, 34, 777-783. [CrossRef] [PubMed]

13. Barnett, K.; Mercer, S.W.; Norbury, M.; Watt, G.; Wyke, S.; Guthrie, B. Epidemiology of Multimorbidity and Implications for Health Care, Research, and Medical Education: A Cross-Sectional Study. Lancet 2012, 380, 37-43. [CrossRef]

14. Corsonello, A.; Pedone, C.; Incalzi, R. Age-Related Pharmacokinetic and Pharmacodynamic Changes and Related Risk of Adverse Drug Reactions. Curr. Med. Chem. 2010, 17, 571-584. [CrossRef] [PubMed]

15. Idescat. Statistical Yearbook of Catalonia. Available online: https:/ / www.idescat.cat/pub/?id=aec\&lang=en (accessed on 27 November 2019).

16. Memòria D’activitats 2012. Institut Català de la Salut. Available online: http://ics.gencat.cat/es/detall/publicacio/memoria_20 12-00007 (accessed on 30 November 2019).

17. Ramos, R.; Balló, E.; Marrugat, J.; Elosua, R.; Sala, J.; Grau, M.; Vila, J.; Bolíbar, B.; García-Gil, M.; Martí, R.; et al. Validez Del Sistema de Información Para El Desarrollo de La Investigación En Atención Primaria (SIDIAP) En El Estudio de Enfermedades Vasculares: Estudio EMMA. Rev. Esp. Cardiol. 2012, 65, 29-37. [CrossRef] [PubMed]

18. García-Gil, M.; Hermosilla, E.; Prieto-Alhambra, D.; Fina, F.; Rosell, M.; Ramos, R.; Rodriguez, J.; Williams, T.; Van Staa, T.; Bolíbar, B. Construction and Validation of a Scoring System for the Selection of High-Quality Data in a Spanish Population Primary Care Database (SIDIAP). Inform. Prim. Care 2011, 19, 135-145. [CrossRef] [PubMed]

19. Calderón-Larrañaga, A.; Vetrano, D.L.; Onder, G.; Gimeno-Feliu, L.A.; Coscollar-Santaliestra, C.; Carfí, A.; Pisciotta, M.S.; Angleman, S.; Melis, R.J.F.; Santoni, G.; et al. Assessing and Measuring Chronic Multimorbidity in the Older Population: A Proposal for Its Operationalization. J. Gerontol. Ser. A Biol. Sci. Med. Sci. 2017, 72, 1417-1423. [CrossRef]

20. WHO. The Anatomical Therapeutic Chemical Classification System with Defined Daily Doses (ATC/DDD); WHO: Geneva, Switzerland, 2010.

21. Masnoon, N.; Shakib, S.; Kalisch-Ellett, L.; Caughey, G.E. What Is Polypharmacy? A Systematic Review of Definitions. BMC Geriatr. 2017, 17, 1-10. [CrossRef]

22. Elorza-Ricart, J.M.; Tovillas-Morán, F.J.; Oliveras-Puig, A.; Galcerán, J.M.; Fina, F.; Dalfó-Baqué, A. Estudio Transversal Comparativo de Las Fórmulas CKD-EPI y MDRD-4 a Partir de La Historia Clínica Informatizada de Atención Primaria de Barcelona. Hipertens. Riesgo Vasc. 2012, 29, 118-129. [CrossRef]

23. Troncoso-Mariño, A.; López-Jiménez, T.; Roso-Llorach, A.; Villén, N.; Amado-Guirado, E.; Guisado-Clavero, M.; FernándezBertolin, S.; Vigues, M.P.; Foguet-Boreu, Q.; Violán, C. Medication-related Problems in Older People in Catalonia: A Real-world Data Study. Pharmacoepidemiol. Drug Saf. 2020, 1-9. [CrossRef]

24. Forns, J.; Cainzos-Achirica, M.; Hellfritzsch, M.; Morros, R.; Poblador-Plou, B.; Hallas, J.; Giner-Soriano, M.; Prados-Torres, A.; Pottegård, A.; Cortés, J.; et al. Validity of ICD-9 and ICD-10 Codes Used to Identify Acute Liver Injury: A Study in Three European Data Sources. Pharmacoepidemiol. Drug Saf. 2019, 28, 965-975. [CrossRef]

25. Domínguez-Berjón, M.F.; Borrell, C.; Cano-Serral, G.; Esnaola, S.; Nolasco, A.; Pasarín, M.I.; Ramis, R.; Saurina, C.; Escolar-Pujolar, A. Construcción de Un Índice de Privación a Partir de Datos Censales En Grandes Ciudades Españolas (Proyecto MEDEA). Gac. Sanit. 2008, 22, 179-187. [CrossRef]

26. Thesaurus Des Interactions Médicamenteuses; Agence Nationale de Sécurité du Médicament et des Produits de Santé (ANSM): Saint-Denis, France, 2018.

27. Joint Formulary Committee. British National Formulary (BNF). Available online: https://about.medicinescomplete.com/ publication/british-national-formulary / (accessed on 30 November 2019).

28. Lexicomp ${ }^{\circledR D}$ rug Interactions-UpToDate. Available online: https://146.219.19.12/drug-interactions/?source=responsive_home\# di-disclaimer (accessed on 27 November 2018).

29. Pautes per a l'harmonització Del Tractament Farmacològic de La Malaltia Renal Crònica. In Programa d'Harmonització Farmacoterèutica de Medicaments en l'Àmbit l'Atenció Primària i Comunitària del Servei Català la Salut; Agència de Qualitat i Avaluació Sanitàries de Catalunya: Barcelona, España, 2014; pp. 1-31.

30. Consejo General de Colegios Oficiales de Farmacéuticos. Botplusweb.portalfarma.com. BOT Plus 2. Base de Datos de Medicamentos. Available online: https:/ / botplusweb.portalfarma.com/botplus.aspx?accion=INICIO (accessed on 27 November 2019). 
31. Delgado Silveira, E.; Montero Errasquín, B.; Muñoz García, M.; Vélez-Díaz-Pallarés, M.; Lozano Montoya, I.; Sánchez-Castellano, C.; Cruz-Jentoft, A.J. Mejorando La Prescripción de Medicamentos En Las Personas Mayores: Una Nueva Edición de Los Criterios STOPP-START. Rev. Esp. Geriatr. Gerontol. 2015, 50, 89-96. [CrossRef]

32. Samuel, M.J. American Geriatrics Society 2015 Updated Beers Criteria for Potentially Inappropriate Medication Use in Older Adults. J. Am. Geriatr. Soc. 2015, 63, 2227-2246. [CrossRef]

33. Stefanie, H.; Sven Schmiedl, P.A.T. Potentially Inappropriate Medications in the Elderly: The PRISCUS List. Dtsch Arztebl Int. 2010, 107, 543-551. [CrossRef]

34. Laroche, M.L.; Charmes, J.P.; Merle, L. Potentially Inappropriate Medications in the Elderly: A French Consensus Panel List. Eur. J. Clin. Pharmacol. 2007, 63, 725-731. [CrossRef]

35. Matanović, S.M.; Vlahovic-Palcevski, V. Potentially Inappropriate Medications in the Elderly: A Comprehensive Protocol. Eur. J. Clin. Pharmacol. 2012, 68, 1123-1138. [CrossRef] [PubMed]

36. Ferrandis Tebar, V.; Moreno Sánchez, E.; Obreo Pintos, J.; Viñuela Álvarez, D. Revisión de La Medicación En El Paciente Anciano. In Listado de Medicamentos Susceptibles de Ser Inadecuados; Junta de Castilla y León: León, España, 2018.

37. Notas informativas de La AEMPS-Agencia Española de Medicamentos y Productos Sanitarios. Available online: https://www. aemps.gob.es/acciones-informativas /notas-informativas-de-la-aemps/?cat=49\&tag=seguridad-8 (accessed on 27 November 2019).

38. Durán, C.E.; Azermai, M.; Stichele, R.H.V. Systematic Review of Anticholinergic Risk Scales in Older Adults. Eur. J. Clin. Pharmacol. 2013, 69, 1485-1496. [CrossRef]

39. Rochon, P.A. Drug Prescribing for Older Adults; Schmader, K.E., Givens, J., Eds.; Uptodate: Waltham, MA, USA, 2020.

40. Woosley, R.L.; Heise, C.W.; Gallo, T.; Tate, J.; Woosley, D.; Romero, K.A. QTdrugs List. Available online: www.CredibleMeds.org (accessed on 27 November 2019).

41. Mannucci, P.M.; Nobili, A.; REPOSI Investigators. Multimorbidity and Polypharmacy in the Elderly: Lessons from REPOSI. Intern. Emerg. Med. 2014, 9, 723-734. [CrossRef] [PubMed]

42. Pintor-Mármol, A.; Baena, M.I.; Fajardo, P.C.; Sabater-Hernández, D.; Sáez-Benito, L.; García-Cárdenas, M.V.; Fikri-Benbrahim, N.; Azpilicueta, I.; José, F.M. Terms Used in Patient Safety Related to Medication: A Literature Review. Pharmacoepidemiol. Drug Saf. 2012, 21, 799-809. [CrossRef] [PubMed]

43. Cahir, C.; Fahey, T.; Teeling, M.; Teljeur, C.; Feely, J.; Bennett, K. Potentially Inappropriate Prescribing and Cost Outcomes for Older People: A National Population Study. Br. J. Clin. Pharmacol. 2010, 69, 543-552. [CrossRef] [PubMed]

44. Dima, M.Q.; Jocelyn, W.; Philip, L.S.; Victoria Gillet, G.C.A. Changes in Prescription and Over-the-Counter Medication and Dietary Supplement Use Among Older Adults in the United States, 2005 vs 2011. JAMA Intern. Med. 2016, 176, 473-482. [CrossRef]

45. Tesfaye, W.H.; Castelino, R.L.; Wimmer, B.C.; Zaidi, S.T.R. Inappropriate Prescribing in Chronic Kidney Disease: A Systematic Review of Prevalence, Associated Clinical Outcomes and Impact of Interventions. Int. J. Clin. Pract. 2017, 71, 1-16. [CrossRef]

46. Moriarty, F.; Bennett, K.; Fahey, T.; Kenny, R.A.; Cahir, C. Longitudinal Prevalence of Potentially Inappropriate Medicines and Potential Prescribing Omissions in a Cohort of Community-Dwelling Older People. Eur. J. Clin. Pharmacol. 2015, 71, 473-482. [CrossRef] [PubMed]

47. Bruin-Huisman, L.; Abu-Hanna, A.; Van Weert, H.C.P.M.; Beers, E. Potentially Inappropriate Prescribing to Older Patients in Primary Care in the Netherlands: A Retrospective Longitudinal Study. Age Ageing 2017, 46, 614-619. [CrossRef] [PubMed]

48. Classen, D.C.; Pestotnik, S.L.; Evans, R.S.; Lloyd, J.F.; Burke, J.P. Adverse Drug Events in Hospitalized Patients: Excess Length of Stay, Extra Costs, and Attributable Mortality. JAMA 1997, 277, 301-306. [CrossRef]

49. Munir, P.; Sally, J.; Shaun, M.; Chris, G.; Andrew, K.S.; Thomas, J.W.; Keith Farrar, B.; Kevin Park, A.M.B. Adverse Drug Reactions as Cause of Admission to Hospital: Prospective Analysis of 18820 Patients. BMJ 2004, 329, 15-19. [CrossRef]

50. Schmiedl, S.; Rottenkolber, M.; Hasford, J.; Rottenkolber, D.; Farker, K.; Drewelow, B.; Hippius, M.; Saljé, K.; Thürmann, P. Self-Medication with over-the-Counter and Prescribed Drugs Causing Adverse-Drug-Reaction-Related Hospital Admissions: Results of a Prospective, Long-Term Multi-Centre Study. Drug Saf. 2014, 37, 225-235. [CrossRef]

51. Farmer, C.; Fenu, E.; O'Flynn, N.; Guthrie, B. Clinical Assessment and Management of Multimorbidity: Summary of NICE Guidance. BMJ 2016, 354, 1-5. [CrossRef] 